\title{
Indigenous medical knowledge for integrated public health development: a new way to reduce poverty in West Java, Indonesia
}

\author{
R.M. Febriyanti ${ }^{1,2, *}$ \\ ${ }^{1}$ Faculty of Pharmacy Universitas Padjadjaran, Indonesia / \\ ${ }^{2}$ LEAD Programme, Leiden University, The Netherlands \\ *Corresponding author : raden.maya@unpad.ac.id
}

\begin{abstract}
Poverty and economic development in Indonesia are directly linked to the access to public health care. Globalisation changes socio-cultural contexts of the community, using the top-down approach rather than the bottom-up approach of primary health care development by ignoring traditional medical systems.
\end{abstract}

Traditional medicine is not only a part of local health practices and traditional indigenous knowledge but has also become a formal strategy to improve primary health care (WHO Traditional Medicine Strategy 2014-2023). The development of traditional medicine is an innovative way to reduce poverty and increase public health through its integration into new forms of integrated microfinance management, implemented through local institutions. Indonesia consists of about 400 ethno-cultural groups, where each group has inherited their specific indigenous knowledge systems from generation to generation, including traditional knowledge of therapies and medicines.

The potential benefits of traditional medicine should not be underestimated. Apart from its contribution to reduce high-prevalence diseases in Indonesia, the problem of persistent poverty could also be resolved since traditional medicine is not only a relatively cheap way of treatment, but is also marketable and can as such be an important source of income and employment for local people.

This paper aims to review evidence on the role of indigenous medical knowledge on the improvement of the current health system and the related reduction of poverty. It is important that all communities take the opportunity to integrate indigenous medical knowledge and practice into local community services, such as in integrated microfinance management in order to improve Indonesia's health agenda while conserving the local cultures.

Keywords: indigenous knowledge, traditional medicine, poverty, public health.

\section{INTRODUCTION}

Economic growth in Indonesia has led to a gradual reduction of overall poverty in the country, which reduced from 17 percent in 2004 to 11 percent in 2014, making Indonesia the third largest economy in Southeast Asia (www.trading- economics.com). On the other hand, approximately 68 million of Indonesians are still living slightly above the national poverty line. This 'near poor' condition of more than $30 \%$ of Indonesians are a result of a financial crisis, health problems, and environmental hazards which may lead people into poverty (Aji, 2015).

Several scholars have reviewed a variety of quantitative methods to measure poverty and suggest that poverty is a multidimensional social phenomenon. Poverty can be defined as the social condition of chronic insecurity due to the malfunctioning of the economic system, or through cultural, ecological and social causes and people lose the ability to adapt and survive and to live and meet their needs and aspirations (Opschoor, 2007).

The World Bank (2006) documents that nearly half of Indonesia will be classified as experiencing at least one type of poverty if all dimensions of human well-being are considered (education, health, employment, housing, sanitation, vulnerability, participation and rights). One of the remarkable traits of poverty in Indonesia is that there is a significant difference in relative and absolute 
poverty dependent of the geographic location. In term of absolute poverty, more than half of the poor people in Indonesia live on Java. In 2014, the ASEAN Development Bank published the statistics of poverty in rural areas in West Java as 12.1\% (Aji, 2015).

Health care has been identified as an essential human need, in addition to other primary needs, such as shelter, food, clothing, clean water and education in the wider context of community development (Walt \& Rifkin, 1990). Health costs in Indonesia have increased significantly during the 2000 to 2010 period. Even the increase in health care costs has been much greater than the rate of inflation during the same period. Based on data from the World Health Organization (WHO), expenditure on health in Indonesia per capita per year in 2001 reached 16,57 US dollars. This number increased to 30,15 US dollars, and rose to 82 percent in 2005 (http://nasional.republika.co.id).

WHO (2004) showed that about half the population in developing countries do not have adequate access to public health services. This condition is influenced by financial constraints associated with rapid population growth, political instability and poor economic performance. Poor people are also significantly affected by the privatisation of health services and hospitals, because these services are more oriented towards rich people. Moreover, policies related to the provision of drugs at affordable prices pose a threat to pharmaceutical companies because of the competition in the global market. Finally, the rapid growth of unemployment and poverty has added to the health problems of the nation by creating extra demand on government services.

\section{METHOD}

We reviewed available evidence and summarised available data sources on: poverty, correlation of poverty and healthcare, and traditional knowledge on medicine. Literature review was conducted in September 2016. The following key words were used ((poverty [Title/Abstract] OR "health problems" AND Indonesia [Title/Abstract]), indigenous knowledge system, traditional medicines, integral healthcare, health system, Indonesia - these were used in Google. Author did not put any time limits or language restrictions.

\section{RESULTS}

INDIGENOUS KNOWLEDGE ON TRADITIONAL MEDICINE IN WEST JAVA

Traditional Medicine is defined by the World Health Organisation (WHO, 1978a) as the sum total of knowledge or practices whether explicable or inexplicable, used in diagnosing, preventing or eliminating a physical, mental or social disease which may rely exclusively on past experience or observations handed down from generation to generation, verbally or in writing. Traditional medicine is also composed of a therapeutic practice that has existed for hundreds of years before the development of modern medicine. Traditional medicine became the best alternative treatment for most of the global population because of its intrinsic quality, unique and holistic approach as well as its accessibility and affordability. Traditional medicine is increasingly popular to treat many health problems - information on traditional use by adults showed that between $33 \%$ and $50 \%$ of the population have tried at least one form of traditional medicine (Mason, 2002).

Overall, the concept of traditional medicine is closely linked to the idea of Indigenous Knowledge Systems (IKS), which is in line with the definition of 'indigenous' by Warren, Slikkerveer \& Brokensha (1995) - 'the local knowledge that is unique to a given culture or society (and) contrasts with the international knowledge system which is generated through the global network of universities and research institutes. In particular, IKS in the health sector have been referred to as Indigenous Medical Knowledge Systems and have been defined as empirical and sacred frameworks for understanding health and healing, which include a specific cosmovision as well as a perceived order in nature (Warren, Slikkerveer \& Brokensha, 1995).

Traditional herbal medicine is a cultural heritage which has been handed down from generation to generation. Initially, plants used for home-remedies were cultivated in home-gardens, called Apotek Hidup (Living Pharmacy). More recently, the use of medicinal plants as well as the cultivation of medicinal plants for the family (tanaman obat keluarga or TOGA) has contributed to building up the knowledge of medicinal plants among the local people (Slikkerveer \& Slikkerveer, 1995).

As every society has established its own medical system conforming to its culture, a medical system can have 
different meaning in every society. The medical system of one society can be very complex because it may consist of several sub-medical systems, which are all available to the people, who therefore can choose which system fits their requirements best. Long before the emergence of the modern medical system, various medical systems already existed in Indonesia, all more or less connected to different ethnic groups and the historical process of the nation. As Slikkerveer (1990) states, the various medical traditions are dynamic and it is appropriate that co-existing systems interact. Meanwhile Foster \& Anderson (1978) point out that these medical systems have something in common, namely that every medical system is an integral part of a culture, that is, illness is culturally defined; therefore in every culture different symptoms are accepted as indicators that someone is ill.

Indigenous knowledge in West Java is the information base unique to the local culture and forms the basis for local-level decision-making in healthcare, agriculture, food preparation, natural resource management, way of life and other social and rural activities. This knowledge, in most cases, is handed down from one generation to another. Traditional medicine or Ethnomedicine is one such indigenous system of knowledge, which has affected the lives of people around the globe. This includes the healing methods and health practices, which are dynamic and are continually influenced by internal creativity and experimentation as well as by the interplay of a complex of social, economic and political factors (Ambaretnani, 2012).

\section{INTEGRATING THE INDIGENOUS KNOWLEDGE ON TRADITIONAL MEDICINE INTO PUBLIC HEALTH CARE SYSTEM}

Slikkerveer (2007) states that of the three major Millennium Development Goals (2000) of poverty reduction, health and education, poverty reduction has now been recognized as the first target. The body of evidence for the impact of microfinance on poverty has now grown to such a level that it irrefutably proves that it works as a poverty alleviation mechanism, provided the services target the poor and the institution is wellrun. In fact, a growing body of knowledge supports the assertion that microfinance is a useful strategy for alleviating global poverty.

In rural areas, the concept of modern science has not been fully accepted by society. Instruments available to reduce poverty in rural areas depend on indigenous knowledge, traditional practices and participation in local institutions. Development for poor people seems to give them no other choice than to investigate the potential of traditional practices to adopt better technology, and be receptive of any innovation to minimize poverty (Mammo, 1999). Furthermore, traditional knowledge systems benefit rural societies because of their cost effectiveness and environmentally friendliness, promoting local consumption and being locally managed. They can combine traditional methods of working with other knowledge systems (Duc, 2006).

The reduction of poverty should not be based on the elimination of western education systems, but these systems should complement traditional knowledge systems within local societies. Economic development and the existence of other knowledge systems affect traditional knowledge and can induce the loss of heritage and diversity. Development can occur without the erosion of traditional knowledge (Sillitoe, 1998). This approach is supported by the neo-endogenous development idea . As cited from Gary et al. (2016) "Neo-endogenous rural development depends on 'bottom-up' activities that integrate external influences to increase local potential. This local focus calls for local knowledge, local resources and the engagement of local people to be central to development processes".

This does not seek to push aside national or regional institutions of the state but 'the goal is to achieve partnership and long-term co-operation among various social actors' (Gorlach and Adamski, 2007)

Traditional knowledge can only contribute effectively to development with support from the government. The Government of Indonesia should promote traditional knowledge as a social and economic mechanism in common with Western knowledge system (Brush, 1993). Promotion of traditional knowledge, in particular traditional medical knowledge, requires effective protection mechanisms to achieve its economic potential.

Participation, as a development strategy, meant to combine and utilise indigenous knowledge that is applicable in a country, to change local people from passive recipients to active producers. Experience from several countries in Asia, such as China and Japan, show that the integration of the health care system of traditional and modern origin can help solve health problems and the high cost of treatment. 
The World Health Organisation (WHO) has not only recommended the integration of traditional medicine in formal health care systems around the globe, but has also promoted the accumulation of research-based knowledge on medicinal plants and the related evaluation and tests of their efficacy and safety within the framework of Primary Health Care (PHC) (WHO, 1978).

Failing to acknowledge the role indigenous knowledge plays in health issues, medical social sciences tend to rely on socio-economic suppositions to explain changes in local patterns (what type of patterns?) in Indonesia. The focus of medical social science should be both trans- and interdisciplinary. Indigenous knowledge systems (IKS) as these have enabled local communities to live and survive in their environments for many generations. Within the context of socio-economic development, these indigenous knowledge systems have shown to be of great potential value for achieving sustainability in various sectors of the community, including traditional ecological systems (TEK), traditional philosophy of nature and the environment, agro-ecosystems, traditional medicine (TM), community development (CD) and the conservation of bio-cultural diversity (BCD), not only for the indigenous communities concerned, but beyond to include the entire humankind around the globe (Slikkerveer, 1995).

IKS become an alternative strategy of a 'bottom-up approach' also known as the cultural dimension of development to contribute to the solution of the prolonged problem of poverty of indigenous peoples in developing countries. Research on IKS has been carried out among rural communities, particularly within the geographical regions of: Southeast Asia (cf. Agung 2005; Leurs 2010; Djen Amar 2010; Ambaretnani 2012); and East Africa (Slikkerveer 1990; Ibui 2007; Chirangi 2013).

The development of safe, effective and affordable traditional medicines and their local production, is a step forward to resolving many health issues. The economic and medical role traditional medicine play are intertwined with legal protection, policies and regulations. Several efforts have been targeted by the WHO to establish possible benefits of integrating traditional knowledge into the mainstream of medical practice, either through the development of new drugs, quality control or standardisation of traditional remedies. The potential use of medicinal herbs in primary healthcare, criteria for the selection of plants for further research or immediate use, and the use of specific remedies in different countries should be studied along with different methodological research approaches for the development of herbal products and models for their clinical evaluation. This must be done if we strive to strengthen the role of herbal remedies in integrative health care as a contribution to the solution of the prolonged problem of poverty of indigenous peoples.

\section{CONCLUSION}

The traditional knowledge of indigenous people has been ignored in the era development and globalisation. Global socio-economic development and change have put the traditional ways of life under pressure and have set aside indigenous peoples and their livelihood.

West java, consisting of several ethnic group, people have many knowledge systems handed down from generation to generation, including traditional knowledge of therapies and medicines. The potential of traditional medicine can be a useful strategy for alleviating poverty. Its integration into Public Health Care System can help solve health problems and the high cost of treatment.

\section{ACKNOWLEDGEMENT}

The author would like to thank Prof. Dr. Dr. (h.c.). L.J Slikkerveer for expert guidance and professional advice in the writing of this paper. We also would like to thank to The LEAD Programme for funding the publication of this paper. The LEAD Programme has supported the provision of a substantial number of studies, which have been carried out in various subfields of ethno-science, such as ethno-medicine, ethno-agriculture, traditional ecological knowledge systems, ethnobotany and integrated microfinance management.

\section{REFERENCES}

Petrie KJ, Muller JT, Schirmbeck F, Donkin L, Broadbent E, Ellis CJ, et al. Effect of providing information about normal test results on patients' reassurance: randomised controlled trial. British Medical Journal. 2007;334(7589): 352-254. Available from: doi:10.1136/ bmj.39093.464190.55 [Accessed 27 August 2015].

\section{Indonesia GDP Annual Growth Rate,} Available online on http://www.tradingeconomics.com/Indonesia/gdpgrowth-annual (accessed on September 1st, 2016) 
Agung, AAG.Bali Endangered Paradise? Tri Hita Karana And The Conservation Of The Island's Biocultural Diversity. Phd Thesis, Leiden University, Leiden; 2006.

Aiglsperger, J. Yiatrosofia Yia Ton Anthropo: Indigenous Knowledge Of Medicinal, Aromatic, And Cosmetic (MAC) Plants In The Utilisation Of The Plural Medical System In Pirgos And Praitoria For Community Health Development In Rural Crete, Greece. Phd Thesis : LEAD Leiden University, Leiden; 2014.

Aji, Priasto. Summary Of Indonesia's Poverty Analysis. ADB Papers On Indonesia. 2015; No.4

Ambaretnani, P. Paraji And Bidan In Rancaekek: Integrated Medicine For Advanced Partnerships Among Traditional Birth Attendants And Community Midwives In The Sunda Region Of West Java, Indonesia. Phd Thesis : Leiden; 2012

Brush, SB. Farmers' Rights And Protection Of Traditional Agricultural Knowledge, World Development, 2007 ;35(9):1499-1514.

Chirangi, MM. Afya Jumuishi: Towards Interprofessional Collaboration Between Traditional And Modern Medical Practitioners In The Mara Region Of Tanzania. Phd Thesis : Leiden University, Leiden; 2013

Bosworth, G., Rizzo, F., Marquardt, D., Strijker, D., Haartsen, T., Thuesen, AA. Identifying social innovations in European local rural development initiatives, Innovation: The European Journal of Social Science Research, 2016; 1 (14)

Gorlach, K. and Adamski, T. Neo-endogenous development and the revalidation of local knowledge. Polish Sociological Review 4, 2007; (16).481-497

Ibui, A. K. Indigenous Knowledge, Belief and Practice of Wild Plants among the Meru in Kenia: Past and Present Human-Plant Relations in East Africa. PhD Thesis : Leiden University, Leiden; 2007

Leslie, C. M. (Ed.). Asian Medical Systems: A Comparative Study. Berkeley : University of California Press; 1976

Mason, S., Tovey, P., Long, AF. Evaluating Complementary Medicine: Methodological Challenges of Randomised Controlled Trials, British Medical Journal; 2002, 325:832-834.

Opschoor, JB. Environment and Poverty: Perspectives Propositions, Policies. Institute of Social Studies Netherlands January 2007. Available onine on www.iss.nl/workingpapers accessed 24 June 2007
Sillitoe, P. The Development of Indigenous Knowledge. Current Anthropology; 1998 (39) 223-252

Slikkerveer, L. J. Traditional Medical Systems and the Challenge of Validation: Towards a. Model of Transcultural Medicinal Use in Indonesia', in: Quah, S.R. and L.J. Slikkerveer (Eds.) Traditional Healing Systems: Negotiating Science and Technology Challenges. Indigenous Knowledge Systems Research and Development Studies No.4, pp 37-56, Singapore, Leiden: LEAD; 2003

Slikkerveer, LJ and Slikkerveer, MKL. Taman Obat Keluarga (TOGA): Indonesian Medicine for SelfReliance, in Warren D.M., L.J. Slikkerveer and D. Brokensha (eds.) The Cultural Dimension of Development: Indigenous Knowledge Systems, London: Intermediate Technology Publications; 1995

Slikkerveer, LJ. Plural Medical Systems in the Horn of Africa: The Legacy of 'Sheikh'Hypocrates, London: Kegan Paul International; 1990

Slikkerveer, LJ. The Challenge of Non-Experimental Validation of MAC Plants: Towards a Multivariate Model of Transcultural Communication on Medicinal, Aromatic and Cosmetic Plants, in: Bogers, R.J., L.E. Craker, \& L. Dagmar (eds.) Medicinal and Aromatic Plants, Agricultural, Commercial, Ecological, Legal, Pharmacological and Social Aspects, Dordrecht, The Netherlands: Springer; 1990

Slikkerveer, LJ. The Need for Integrated Microfinance Management to Reduce Poverty and Enhance Health and Education in Indonesia, LEAD, Leiden University; 2007

Walt, G. and Rifkin, S. The Political Context of Primary Health Care. In P. Streefland \& J. Chabot (Eds.), Implementing Primary Health Care. Experiences since Alma-Ata. Amsterdam: Royal Tropical Institute; 1990

World Bank. Indonesia Economic Quarterly July 2014. Jakarta. 2 BPS-Statistics Indonesia. 2015. Poverty Statistics.; 2014. Available online on http://www.bps.go.id/linkTabelStatis/view/id/148 $\underline{8 \text { accessed at } 2 \text { September } 2016 .}$

World Health Organization. Primary Health Care, Report of the International Conference on Primary Health Care, Alma-Ata, USSR, 6-12 September, Geneva; 1978.

World Health Organization, South-East Asia Region. Health Situation in South East Asia, Regional Office for South-East Asia; 2014. 